Canadian Journal of Family and Youth, 8(1), 2016, pp 129-151

ISSN 1718-9748 (C) University of Alberta

http://ejournals.library.ualberta.ca/index/php/cjfy

\title{
Former Young Carers Reflect on Their Caregiving Experience
}

\author{
Olga Szafran, Jacqueline Torti, Earle Waugh and Kimberley Duerksen
}

\begin{abstract}
Using focus group methodology, this study explored the experiences of young carers from the perspective of former young carers in Edmonton, Alberta. The study findings reveal that being a young carer has a significant impact on a young person's life that extends well into adulthood. Former young carers recalled being burdened with household responsibilities, as well as with providing direct care to a family member. They generally had negative school experiences that included being bullied and feeling that the system ignored their suffering. They felt physically and emotionally tired and stressed, lonely, and socially withdrawn. Despite their stresses, they wanted to keep their situation a secret, for fear of external interference into their family. While females recalled deriving some positive benefits from the young caregiving experience, males saw absolutely no benefits. As adults, they perceived that being a young care had affected their social development and the formation of personal relationships into adulthood. Young carers in Edmonton are a hidden and vulnerable population who appear to suffer in silence. The lack of societal recognition has impeded the development of support systems for young carers.
\end{abstract}

Olga Szafran, MHSA, is Associate Director of Research, Department of Family Medicine, University of Alberta. She has conducted research in the area of cultural issues in health care, family physician practice patterns, medical education, international medical graduates, and primary health services research, and has published on these topics. She co-edited the book At the Interface of Culture and Medicine (2011) published by the University of Alberta Press and co-authored Cultural Competency Skills for Health Professionals: A Workbook for Caring Across Cultures (2014) published by Brush Education Inc. Jacqueline Torti, MA, is a PhD candidate in the School of Public Health at the University of Alberta. She works as a Graduate Research Assistant in the Department of Family Medicine at the University of Alberta. She is a qualitative methodologist whose research is focused on psychosocial aspects of health and well-being. She has co-authored the article "Is There a Care Gap for Young Carers in Canada? Edmonton Community Agency Perspectives" (2015) in the Canadian Journal of Family and Youth. Earle Waugh, PhD, is CoDirector of the Centre for Health and Culture, Department of Family Medicine, Faculty of Medicine and Dentistry, University of Alberta and a former Director of Education and Research for the Alberta Caregivers Association. He has published widely on topics of health and intercultural understanding. His recent article on teenaged pregnancy among Aboriginal youth has been downloaded nearly 500 times. He is currently completing a project on bioethical issues for Muslims in Canada. Kimberley Duerksen, MSc, is Research Coordinator in the Department of Family Medicine, University of Alberta. She has a background in pharmacology and has worked in family medicine research for the past eight years. She has an interest in qualitative and quantitative methodology.

Acknowledgements: This study was funded by the Alberta Centre for Child, Family \& Community Research. 


\section{Introduction}

Young carers are "children and young people under 18 who provide regular or ongoing care and emotional support to a family member who is physically or mentally ill, disabled or misuses substances" (ADASS, ADCS \& The Children's Society, 2012). While, to some degree, caring for others is both acceptable and expected as a healthy behavior in the development of a young person, the caring responsibilities of young carers usually go above and beyond what would be expected, given developmental, social, and cultural norms and age (Aldridge \& Becker, 1999; Charles 2014).

While the prevalence of young carers in Canada is unknown, $12 \%$ of young people in a British Columbia secondary school reported taking on significant caregiving roles in their families (Charles, Marshall \& Stainton, 2010). In the United States, it is estimated that 3.2\% of households with young people have young carers (Becker, 2007; Hunt, Levine \& Naiditch, 2005). The prevalence of young carers is estimated to be between $3.6 \%$ and $7.4 \%$ in Australia (Barber \& Siskowski, 2008; Pakenham, Chiu, Bursnall \& Cannon, 2007; Richardson, Jinks \& Roberts, 2009) and between 3\% and 8\% in the United Kingdom (Aldridge \& Becker, 1993; Shifren \& Kachorek, 2003; Stewart \& Patterson, 2010). Much of what is known about young carers comes from studies conducted outside of Canada.

Young caregiving typically starts with the onset of an illness or disease in the immediate family, along with a combination of other factors that leave young people with no choice but to become primary caregivers within their homes (Aldridge, 2008; Metzing-Blau \& Schnepp, 2008). A young person's caregiving responsibilities depend on the severity of the care recipient's illness/condition and its stage of progression. Young carers are more typically found in single- 
Former Young Carers

parent families and care more often than not for their parent. In the absence of a second parental figure, these young people assume the role that would generally be taken on by their parent's adult partner (Aldridge, 2008; Newman, 2002). Young caregiving may also be a consequence of inadequate parenting or the parent's need for the child's assistance (Newman, 2002). Families of low socioeconomic status who may lack financial and other resources needed to pay for and access necessary care are also more likely to have young people in caregiving roles (Becker, 2007; Metzing-Blau \& Schnepp, 2008; Newman, 2002). Gender, age, and birth order are predictors of young caregiving, with girls being more likely than boys to be involved in all caregiving aspects, particularly domestic duties (cooking, cleaning) and intimate care (bathing, dressing) (Banks et al., 2002). In families with multiple children, the oldest child typically bears the most caregiving responsibilities (Gates \& Lackey, 1998). Cultural norms and expectations also influence caregiving responsibilities of children. In some cultural communities it is considered a filial obligation of children to care for sick or aged parents and relatives (Merrel, Kinsella, Murphy, Philpin \& Ali, 2005) and children are typically expected to take on household duties to help out (Skovdal, 2010). Culturally, such caring responsibilities are deemed to be necessary for the socialization of children.

The responsibilities of being the primary caregiver may pose various challenges for young people. Young carers often experience difficulty in school due to high absentee rates, lack of study time, and poor concentration, resulting in poor academic performance and potentially limited post-secondary career options (Banks et al., 2002; Barber \& Siskowski, 2008). In addition, young carers tend to isolate themselves socially for fear of being bullied or appearing different than their peers (Diaz, Siskowski \& Connors, 2007). They are often bullied, mocked, or stigmatized for their family situation or caregiving role (Aldridge, 2008; Grant, Repper \& Nolan, 
Szafran, Torti, Waugh and Duerksen

2008) and reportedly have a harder time making and maintaining friendships (Banks et al., 2001;

Banks et al., 2002; Butler \& Astbury, 2005). Young carers have reported being emotionally drained from feeling helpless seeing their loved ones in pain or watching them slowly deteriorate over time (Lackey \& Gates, 2001). Studies reveal that young carers are often confused, angry, fearful, ashamed, or have strong feelings of resentment (Barber \& Siskowski, 2008; Diaz, Siskowski \& Connors, 2007; Gates \& Lackey, 1998). Young carers are also more likely to worry, have anxiety disorders and exhibit anti-social behaviours (Becker, 2007; Burke \& Montgomery, 2001). In some instances, young carers are denied the basic pediatric care they require due to financial costs, unavailable resources, and lack of parental responsibility (Barber \& Siskowski, 2008). It is common for young carers to suffer from poor nutrition given that they not only lack the essential financial resources to buy healthy foods, but also lack the skills to do the grocery shopping and prepare meals (McClure, 2001).

Being a primary caregiver at a young age can also have positive consequences. Although young caring can result in worry, distress and potential feelings of guilt about the care recipient (Aldridge \& Becker, 1999), Göfert, Webster and Seeman (1996) argue that caring at a young age can actually alleviate worries and stresses. Young people are well aware that their loved one is ill or requires assistance, and by providing care to them directly they feel a sense of relief that they know they are taken care of. Young carers may develop a deep and intimate bond with the care recipient due to the nature of their relationship. For some young carers, taking matters into their own hands can ease their concerns. Other young carers gain a sense of accomplishment or purpose, as well as a sense of being needed and a positive sense of self (Aldridge, 2008; Becker, 2007; Metzing-Blau \& Schnepp, 2008). Given that young carers take on adult-like responsibilities, they are often far more mature than their non-caregiving peers (Becker 2007; 
Former Young Carers

Newman, 2002) and tend to be sensitive, caring, empathetic, and highly independent (Banks et al., 2001). They learn essential life skills at an early age and develop a good understanding of adult issues and of the care recipient's illness or disability (Metzing-Blau \& Schnepp, 2008). Some young carers develop effective coping mechanisms and practical skill sets beyond their years, which help prepare them for adult life (Becker, 2007).

Most of the understanding of why young caregiving is an important and significant issue comes from international research and Canadian data are lacking in this regard. We undertook a study to explore the issues of young carers with the Canadian context from the perspective of former young carers, i.e. to gain insight into what former young carers think and feel about their caregiving experience when they were young people. To our knowledge, our study is the first to explore the experiences of former young carers in Alberta.

\section{Method}

\section{Study Design \& Participants}

A descriptive, exploratory study employing focus group methodology was conducted with five former young carers in Edmonton, Alberta, Canada. This pilot study warranted an exploratory approach as little is known about young carers in Alberta and a qualitative approach was selected to elicit rich responses and draw from the experiences of the participants. Participants were purposefully recruited through community agencies by way of a recruitment notice, as well as snowball recruitment among participants. Within the context of this study, former young carers were defined as adults ( $\geq 18$ years of age at the time of the study) who, prior to the age of 18 years, acted as a caregiver for an ill, disabled, mentally distressed or affected by substance abuse parent or sibling. These were retrospective recollections of their experience as a 
Szafran, Torti, Waugh and Duerksen

caregiver when they were children. Those who expressed interest in taking part in the focus group directly contacted a member of the study team. Ethics approval for the study was obtained from the Health Research Ethics Board (Health Panel) at the University of Alberta.

\section{Focus Groups}

Two small focus groups were led by one member of the study team (JT) who acted as the group facilitator. The two focus groups consisted of two or three participants each. The smallersized focus groups fostered greater participation of individuals within the groups and allowed for more opportunity to share their experiences, as well as facilitated the discussion of sensitive issues (Krueger, 2009). Participants were provided with an information letter describing the study purpose and procedures and provided written consent prior to the commencement of the focus group. Participants were requested to keep confidential all information discussed during the focus group. Focus group participants were asked to address the issues they faced as young carers and the positive and negative impacts that young caregiving had on their lives. Conducted during April and May 2012, the focus groups were approximately 60 minutes in duration and were audiotaped.

\section{Data Analysis}

Audio-taped focus group data were transcribed verbatim by a professional transcriptionist. The transcripts were initially reviewed by two members of the study team and cleaned to remove personally identifiable information. Study participants were assigned pseudonyms to protect their identity. Three members of the study team independently read the transcripts to identify main theme areas and subsequently met several times to reach consensus. Qualitative data analysis was carried out using a descriptive perspective. 
Former Young Carers

\section{Results}

Five participants (Sara, Sally, Jane, Nick and Jake; names have been changed to protect their identities) took part in the focus groups. These former young carers reflected on the family circumstances they grew up in that resulted in them having major caring responsibilities as children. The caring responsibilities usually started with the onset of an illness or disability of a family member or other family circumstances that left them with no choice but to become a caregiver in the home. In some instances, former young carers were in a single or two-parent family with no or few support systems; in other instances, the parents were neglectful and/or abusive and the children were left to look after themselves. Sally grew up in a single parent family with a schizophrenic mother and a younger sister, both of whom she cared for. As a child, she and her sister witnessed her mother's graphic schizophrenic episodes, including episodes of violence and abuse. From the age of five, Nick cared for his single parent mother who had debilitating osteoarthritis which severely restricted her activities of daily living. He was the youngest participant, being in his early twenties, and continued to provide care at the time of the study. Jake cared for his siblings in a household with an alcoholic mother and an alcoholic and abusive stepfather. The parents neglected their caring responsibilities and the children were often unattended and hungry. Sara cared for a younger brother because her parents were mostly absent, either working or out socializing. She spent her childhood raising her younger brother. Jane cared for a severely autistic older brother, in a two-parent family with two other siblings. The caring relationship grew to the point where she was prepared to become his legal guardian. 
Szafran, Torti, Waugh and Duerksen

\section{Issues Faced as Young Carers}

The issues faced by former young carers were categorized into four main themes: (1) caring responsibilities; (2) protecting the family; (3) school; and (4) personal issues and feelings.

\section{Caregiving Responsibilities}

Participants identified three main areas of responsibilities that they encountered as young carers: (a) providing direct care to the care recipient; (b) general household duties; and (c) taking care of siblings. In situations where the care recipient was ill or disabled, former young carers recalled assisting the recipient with basic activities of daily living, such as mobility issues (helping their relative get in and out of bed and moving around the house), wheelchair assisting, dressing and undressing, grooming, feeding, bathing, showering, and helping with toileting.

I was taking more care of her, helping her out of bed, helping her into the shower,...for about four years...So yeah, I did everything. I was her legs, her arms, her eyes, for the outside, everything. (Nick)

Performing domestic duties around the house was frequently discussed by former young carers. This included a broad range of household activities such as cleaning house, washing dishes, doing laundry, preparing meals, shopping, managing money, and dealing with household affairs.

I was doing everything, the groceries, the washing, all the cleaning, all the laundry, all the dishes, absolutely everything... (Nick)

I was preparing food. I was having conversations with our manager in the building that we were renting from. (Sally)

Clean the house, do your chores, clean the house, clean the yard, mow the lawn. (Jake) 
In cases where there were younger children in the family, former young carers spoke of being responsible for taking care of siblings, making sure they ate, went to school, did their homework, and behaved themselves.

I took care of my little brother from the age of 9 until probably 14 or 15 ...he's about 5 years younger than me, so until he could kind of take care of himself. It was pretty much every day after school and whenever my parents felt like leaving it wasn't really an option. (Sara)

...between me and my little sister, we sort of learned to thrive and exist supporting each other... (Sally)

Former young carers recalled depending on, supporting and feeling protective about their siblings, as well as shielding younger siblings from abusive and/or neglectful parents.

\section{Protecting the Family}

Despite the stresses of caring for ill/disabled parents or siblings or growing up in a neglectful home situation, former young carers commented on their desire as young children to keep their family circumstances a secret, to maintain family solidarity, and to keep the family together. There was fear of betraying and ruining the family if the home situation was made known to others. They expressed fear of external interference into their family, i.e. if others found out about their home situation, they could be taken away from their parents, or that their care recipient could be taken away.

I have to say I'm fairly certain that ... [we] ... would've lied through our teeth to keep our mom safe and to not, you know the fear in our minds would've been we're gonna get taken away and Lord knows where we're gonna go, so I don't think if support could've come out of the social workers being in our home, I don't think we would've given them any indication that we wanted it. As much as a 7 year old can convince an adult that they don't need help. (Sally)

Like you want your family to seem normal and appear normal and my parents were afraid that if there were any problems that my brother was going to be taken away, he was going to be locked up in like an all-white room with padded walls and, like that was literally the fear that was communicated to us. So I was always 
very afraid. I didn't think it was safe to talk to anyone about it. So a lot was just sort of like maintaining the family-like appearance, like that we're all OK... could not have a conversation with anyone else because if I did then you know I might lose my whole family. That was the fear. (Jane)

As children, they wanted to remain with their parents, regardless of the home situation.

I wouldn't have wanted me and my sister to be away from my mom even though not everybody would agree that that was the best place for us... (Sally)

Through my whole young part of my life and my adult life I've always thought of my dad as my dad no matter how demeaning or mean or physically or mentally abusive he was, I always wanted to have a dad. (Jake)

In particular, there was fear of government interference and lack of trust in social services and the police. While as young people, they knew that social services and the police were there to help them, they dreaded such interference knowing well what the consequences may be.

...I remember a social worker coming to the school, me getting called out of class to go meet with a social worker who was asking about the abuse at home 'cause the teacher had noticed that I was covered in bruises and I went through the same thing where you have that fear about breaking your family apart and so I didn't speak openly about it...I was protecting my mom because I recognized that she wasn't to blame and I didn't want her to be reprimanded for something that I didn't think was her fault. (Sally)

\section{School}

School plays a major role in young people's lives and former young carers reiterated this. School was a mixed blessing. While on the one hand it was an escape from the stresses at home, on the other hand it presented its own set of problems. Former young carers generally recalled missing a lot of school, being tired and sleeping in class, not having their homework done, getting poor grades, being hungry in school, and not taking part in extra-curricular activities.

I did really well in school just because it was an escape and it was something to do and it was sort of way to get away from the chaos. (Jane)

...they only had their tiny little problems like they had/didn't have a fruit rollup for lunch; woopdeedo, I don't have a frickin' lunch you know. (Nick) 
Some felt that teachers and school counsellors suspected that something was going on with them, but the school system did not know how to deal with them, ignored their suffering, and just let things slide.

...people knew what was going on, but that doesn't necessarily mean that they were going to do anything. (Sara)

Some former young carers reported being bullied by other students, which added to the stress.

I was getting bullied very badly at school and so there was no escape. I'm escaping home and I'm going to school and I'm getting bullied so I was escaping there and I'd just put my head down in class and cried (Jane)

...they made a point of making my life difficult in high school, things like schizophrenic would be written on my locker... (Sally)

Most participants recalled having a negative school experience. One was pulled out of school due to bullying and was home schooled, and another other dropped out of school at the age of 15 years. Only one female former young carer reported being an overachiever and doing well in school; for her, school was an escape. In high school, she joined many clubs, was on student council, had boyfriends, and two part-time jobs. She commented, "I made time to basically spend as much time out of the house as possible" (Sara).

\section{Personal Issues \& Feelings}

Former young carers recalled feeling stressed, burnt out, and exhausted at a young age. The load of caring responsibilities, the demands and pressures of school, and the associated emotional stress affected them deeply. They noted feeling lonely and depressed.

It's when you wake up in the morning and you want to take a nap. I definitely remember feeling exhausted at a young age (Sara)

...we all went through you know depression, feelings of alienation, destructive behaviours... (Sally) 
Szafran, Torti, Waugh and Duerksen

Having different life experiences and perspectives than other young people their age, some found it difficult to relate to other classmates in school. They tended not to share with others what was going on at home for fear of being stigmatized or bullied; as such, tended to become socially withdrawn, lonely, and isolated.

...it can be a really lonely place because the people that you're supposed to be going to are depending on you ... you don't necessarily know where to go beyond that. (Sara)

Participants also commented that "time" was a big issue for young carers, particularly not having time for themselves, for friends, or to do what children their age normally do.

As young carers, they tended to feel that they could not take part in extracurricular activities, given their caregiving responsibilities and transportation barriers.

...no joining any clubs or sports or anything like that because there's none of that because you'd have to get driven to 'em or it'd have to be paid for. (Jake)

\section{Benefits of Young Caregiving}

Participants reflected on the perceived benefits they derived from caring for someone.

Both males and females noted that being a young carer taught them to be responsible at a young age and be independent. They learned to problem-solve at a young age and gained a sense of community responsibility. Among the females, the perception was that the experience of being a young carer made them more understanding, compassionate, and sympathetic. They were able to appreciate and understand their care recipient better.

You learn compassion and understanding and sympathy and your sense of everybody's reality just becomes so different. My personal development has probably been the most amazing aspect out of all of it... and the positives have turned now into I care for my mom differently. I'm a different person who has a different understanding of who she is and how she is and how incredible her mind it. (Sally) 
...it's definitely given me a good work ethic, it's definitely shaped my life in ways that I didn't even understand at the time. It's given me a really good sense of responsibility and also community responsibility as well and, in a lot of ways I think being forced to grow up younger than I should have had, has also made me very aware of the larger world from a younger age... (Sara)

The experience also helped forge strong relationships with the care recipient and/or other family members in the home. This relationship seemed to have developed from sharing the same experience.

I think my brother and I are fairly close now and I've always been the person that he goes to or absolutely needs help and so in a lot of ways I've been able to help him in his life... (Sara)

So the relationship with my sister wouldn't have been the same if we wouldn't have gone through what we did with her because I had a maternal role with her. So we have a very close relationship... You feel like you have somebody who actually understands everything about you because you've been through the same thing together. It's remarkable how close that brings you together. (Sally)

For one female participant, the experience had drawn her to caring roles and relationships and influenced her career choice in the area of disability studies.

Well, it's pointed me in the direction that I want to go for my career, so it's kind of created my whole life...... so I find myself constantly drawn to this sort of motherly caring role and even with a lot of my friendships...I'm ready to help and come up with a plan and try to figure things out, so it's influenced the way I interact with people a lot and it's influenced my relationships a lot and who I choose to spend my time with too. So I'm sort of drawn to that kind of caring role. (Jane)

In contrast, both male participants saw no positive aspect to young caregiving, Absolutely zero. (Jake)

They did not recall any happy memories and wanted to escape the caregiving experience.

You said did I get anything positive out of my care giving role at the time I was caregiver, no. The positive thing I got out of my care giving role was when I left that role and it was positive from there (Jake) 
Szafran, Torti, Waugh and Duerksen

\section{Negative Impact of Young Caregiving}

Former young carers commented that caregiving at a young age had negatively

influenced their social development and the formation of healthy relationships. They found it

difficult to relate to other children and formed few real, positive friendships.

But even to this day I definitely, I don't trust people easily and I have a hard time relating to people in some senses as well, simply because I don't pick up on social cues and I don't always understand people the way that other people understand people...... I always had relationship troubles, I dated terrible guys, ... I had issues with my dad and like low self-esteem and all that ... (Sara)

For one female, the young caregiving experience had temporarily turned her off the idea of marriage and family as she transitioned into adulthood. Growing up she had a skewed idea of motherhood and womanhood.

I grew to resent being depended on and by the time I was 18, not only did I not want to have marriage in my future, I didn't want kids in my future. I did not want anybody depending on me because I, as a caregiving young woman up until that point felt like I'd already raised a family and so my early twenties were spent gaining my independence which was very liberating and it's only been in the last couple of years where I in my continued growth have come to a point now where I cherish my maternal side and look forward to children and my husband and all those wonderful things that come with having people in your life to care about you and for you to love. (Sally)

One male participant expressed strong negative feelings about being a young carer. He resented the caregiving experience and the influence that it had on his life. For him, caregiving at a young age ruined his childhood and he blamed his young carer experience for the shortcomings in his life.

My life has been destroyed for, what I could have been, I could have been successful......it's made my work ethic worse because I don't want to work anymore, because I've done so much work already. I never want to do more than I've already done. (Nick) 
Former Young Carers

Former young carers also recalled acting out and engaging in troubling or illegal activities as a way of coping with the stress of caregiving. These behaviours either resulted in self-harm, or the harm of others.

...I was mouthy and yep I definitely had an attitude on me... and so you know me saying, 'No, I'm not going to empty the dishwasher,' is so much more than no I'm not going to empty the dishwasher, It's like, no I'm not going to do one more fricking thing for you because I just want to go...play soccer. I just want to like just leave me alone for like 5 minutes...my cry for help as a teenager was not eating. I did not eat for a long time... I wouldn't say I was anorexic but I was definitely not healthy. And it was the stress manifesting... (Sara)

\section{Discussion}

Our study exploring a group of Canadian former young carers' recollections of their young caregiving experience reveals that being a young carer has a significant impact on one's life. Family circumstances dictate that young carers assume adult responsibilities early on in life through no choosing of their own. While family circumstances may vary, the caring responsibilities appear to be fairly similar and include providing direct care to the care recipient, performing household duties, and taking care of siblings; consistent with that reported by Banks et al. (2001) and Beards and Barua (2011). The demands of caregiving can affect a young person's physical health (tired), psychological health (stress, loneliness, exhaustion, depression), schooling, and social development (maladjustment, isolation, exclusion, bullying). Similar findings have been reported in the USA (Diaz, Siskowski \& Connors, 2007) and UK (McClure, 2001). The study findings reveal that in some instances, young caregiving can result in some degree of parentification (Newman, 2002; Valleau, Bergner \& Horton, 1995) wherein the young person acts as a parent to their own parent, assuming the household responsibilities of the parent, as well as providing emotional support to the parent. 
Szafran, Torti, Waugh and Duerksen

For young carers, school may be an escape from the caring responsibilities of home, however, it is not a safe haven. For the most part, former young carers in our study reported having a negative school experience, characterized by relatively poor academic performance, a high absentee rate, homework not done, being tired and hungry, being bullied, and/or feeling isolated. This is consistent with research conducted by Banks et al. (2001) where $86 \%$ of the young carers surveyed indicated they had missed some school or had trouble in school as a result of their caring responsibilities. Former young carers also sensed that teachers and counsellors knew about their situation, but ignored their suffering and failed to support them. The lack of school support is reflective of the fact that young carers remain a hidden and unrecognized population in Canada. Lack of societal recognition has meant that community resources have not been allocated in support of young carers (Waugh et al., in press for 2015). Despite this current reality, it is imperative that school professionals are trained to recognize students who have caregiving responsibilities and develop an understanding of the issues and challenges faced by young carers. Supports for young carers within the school system may include providing homework and exam flexibility, in-school tutoring, anti-bullying campaigns, and nutritional programs.

The strong desire by young carers to keep their family situation a secret and to protect the family and maintain family solidarity, even if it means lying and concealing the truth, has also been reported by Rose \& Cohen (2010). This constancy of fear of external interference, particularly from social services and the police, reflects a lack of trust in government institutions and socialized systems. While society must protect vulnerable and abused children, there is a need for social services and community interventions to be sensitive to the fears and needs of young carers (Aldridge \& Becker, 1993). Aldridge (2008) notes that supporting young carers can 
Former Young Carers

be challenge because of the conflict between private family matters and government intervention; it is difficult yet important to understand the difference. Making societal supports voluntary and non-intrusive may help to reduce the stigma around social and family services and encourage young carers to seek assistance if they feel they need it and when they feel ready to do so.

The literature on young carers supports the notion that both males and females benefited from caring at a young age. In fact one study by Joseph and colleagues (2009) found that males participants actually scored significantly higher on the positive sub-scale of the Positive and Negative Outcomes of Caring (PANOC-YC), a 20 item self-report measure. In contrast, our study findings suggest that gender differences may exist related to the effect the caregiving experience has on the young carer. Only females reported any positive aspects to being a young carer, noting that the caring at a young age helped them forge a strong relationship with the care recipient, making them more understanding, compassionate, and sympathetic. For one female, the experience had drawn her to caring roles and influenced her career choice. This gender difference in the study findings is supported by social science theories (Robson, 2004; Ramirez, 2013) that indicate that females tend to be more nurturing, caring and affectionate than males. Women have traditionally assumed caring roles in society and are socialized into caring and nurturing roles. While our study was too small to explore the effect of gender, an examination of the experiences of young carers on the long-term effects into adulthood by gender are worthy of further investigation.

Although the transcribed quotations of the respondents do not readily convey the depth of emotion with which they were spoken, an examination of the audiotapes revealed strong feelings about the young caregiving experience, particularly among male former young carers. This 
suggests that the young caregiving experience may have a profound and lasting emotional impact into adulthood. Some former young carers may continue to have unresolved issues long into adulthood and may benefit from counselling. The period of transition into adulthood, particularly as it relates to forming lasting relationships and issues related to parenthood, may be difficult for some young carers and is worthy of further investigation. While young carers seemingly spend most of their time in a caring role, little time appears to be afforded to social activities with others their age. Limited social interaction may result in young carers lacking some of the social skills and experience needed to build and maintain friendships (Banks et al., 2001; Banks et al., 2002; Butler \& Astbury, 2005, Warren, 2007). Support programs for young carers must include social activities with other young people to encourage social skill development and the building of relationships.

While our study is limited by its small sample size, its strength is the rich qualitative content obtained from the focus group discussions. It is evident that the smaller-sized focus groups created a comfortable and safe environment for participants to open-up and recall their personal and sensitive experiences of being a young carer. The participants may not be representative of all former young carers, but the aim of the study was not to achieve generalizability of findings, but rather to gain insight into the young caregiving experience from the perspective of former young carers. Recall bias is likely given that participants were asked to recall experiences that, for some, occurred anywhere between 10-30 years ago. The recollections of former young carers, however, provided insight into the perceptions of the long-term implications of young caregiving. The findings should be interpreted with some caution as they may not be wholly representative of the experiences of current young carers. 
Former Young Carers

There is need for further studies on young carers in Alberta and in other provinces and territories in Canada. Our study has shown the impact that young caregiving can have on young people and the need for further investigation of their experiences. Studies should examine the impact of the young caregiving experience on the psychological and social development of young people, as well as on their transition into adulthood. Issues related to loss of youth, lack of play, constancy of fear, development of trust, intensity of experience, and development of relationships are worthy of investigation. Analyses of young caregiving by gender and cultural differences in the young caregiving experience also warrant further study. A population-based study is also needed to determine the scope and prevalence of young caregiving across the country. It is essential that the issues and needs of young carers in Canada are examined with the same degree of rigor evidenced in other countries, such that policy and program initiatives can move forward to support these vulnerable young people.

\section{Conclusion}

The recollections of former young carers about their caregiving experience reveal that having major caregiving responsibilities has a significant impact on a young person's physical and psychological health, schooling and social development. The experience is perceived to have a profound lasting influence that carries on into adulthood, adversely affecting the development of social skills necessary to form and maintain relationships. Our study suggests that gender differences may exist in perceptions of positive benefits derived from the young caregiving experience, with females noting that caring at a young age helped them forge a strong relationship with the care recipient, making them more understanding, compassionate, and sympathetic. In contrast, males saw no benefit. The strong desire by young carers to keep their family situation a secret and to protect the family indicates the need for social services and 
Szafran, Torti, Waugh and Duerksen

community interventions to be sensitive to the fears and needs of young carers. Within the Canadian context, societal support for young carers is lacking and addressing the issues and needs of this invisible and vulnerable population will be a challenge until young carers are recognized within our society. 
Former Young Carers

\section{References}

ADASS (Association of Directors of Adult Social Services), ADCS (Association of Directors of Children's Services), \& The Children's Society. (2012). Working together to support young carers and their families. Retrieved from: http://www.adcs.org.uk/download/ position-statements/2012/MoU\%20young\%20carers\%202012.pdf. October 15, 2014.

Aldridge, J. (2008). All work and no play? Understanding the needs of children with caring responsibilities. Children and Society, 22, 253-264. Doi: 10.1111/j.10990860.2007.00094.x

Aldridge, J., \& Becker, S. (1993). Punishing children for caring: The hidden cost of young carers. Children \& Society, 7(4), 376-387.

Aldridge, J., \& Becker, S. (1999). Children as carers: The impact of parental illness and disability on children's caring roles. Journal of Family Therapy, 21, 303-320.

Banks, P., Cogan, N., Deeley, S., Hill, M., Riddell, S., \& Tisdall, K. (2001). Seeing the invisible children and young people affected by disability. Disability \& Society, 16(6), 797-814. doi: 10.1080/09687590120083967

Banks, P., Cogan, N., Riddell, S., Deeley, S., Hill, M., \& Tisdall, K. (2002). Does the covert nature of caring prohibit the development of effective services for young carers. British Journal of Guidance \& Counselling, 30(3), 229-246. doi: 10.1080/030698802100002281

Barber, M., \& Siskowski, C. (2008). Youth caregivers: Unrecognized providers of care. Pediatrics, 93(3), 488-494. doi: 10.1542/peds.2008-0093

Beards, C., \& Barua, K. (2011). Who are Australia's 'hidden' carers? Association of Relatives and Friends of the Mentally Ill. Retrieved from: http://archiveorg.com/page/437883/2012-10-14/http://www.arafmi.org/article/who-are-australia's'hidden'-carers. October 13, 2014.

Becker, S. (2007). Global perspectives on children's unpaid caregiving in the family: Research and policy on 'young carers' in the UK, Australia, the USA and Sub-Saharan Africa. Global Social Policy, 7(23), 23-50. doi: 10.1177/1468018107073892

Burke, P., \& Montgomery, S. (2001). Brothers and sisters: Supporting the siblings of children with disabilities. Practice: Social Work in Action, 13(1), 27-38.

Butler, A. H., \& Astbury, G. (2005). The caring child: An evaluative case study of the Cornwall young carers project. Children \& Society, 19, 292-303. doi: 10.1002/CHI.851

Charles, G. (2014). Position paper on young carers. Vancouver, BC: BC Young Carers Research Group. 
Szafran, Torti, Waugh and Duerksen

Charles, G., Marshall, S., \& Stainton, T. (2010). Demographics, profiles and initial results from the British Columbia Young Carers Study. Relational Child and Youth Care Practice, 23(4), 64-67.

Diaz, N., Siskowski, S., \& Connors, L. (2007). Latino young caregivers in the United States: Who are they and what are the academic implications of this role? Child Youth Care Forum, 36, 131-140. doi: 10.1007/s10566-007-9040-4

Gates, M. F., \& Lackey, N. R. (1998). Youngsters caring for adults with cancer. Journal of Nursing Scholarship, 30, 11-5.

Göpfert, M., Webster, J., \& Seeman, M. V. (1996). Parental psychiatric disorder. Distressed parents and their families ( $\left.2^{\text {nd }} \mathrm{ed}\right)$. Cambridge, UK: Cambridge University Press.

Grant, G., Repper, J., \& Nolan, M. (2008). Young people supporting parents with mental health problems: Experiences of assessment and support. Health and Social Care in the Community, 16(3), 271-281. doi: 10.1111/j.1365-2524.2008.00766.x

Hunt, G., Levine, C., \& Naiditch, L. (2005). Young caregivers in the U.S.: Findings from a national survey. Washington, DC: National Alliance for Caregiving.

Joseph, S., Becker, S., Becker, F., \& Regel, S. (2009). Assessment of caring and its effects in young people: development of the Multidimensional Assessment of Caring Activities Checklist (MACA-YC18) and the Positive and Negative Outcomes of Caring Questionnaire (PANOC-YC20) for young carers. Child: Care, Health and Development, 35(4), 510-520.

Krueger, R.A. (2009) Focus groups: A practical guide for applied research (4 ${ }^{\text {th }}$ ed.). Thousand Oaks, CA: Sage Publications Inc.

Lackey, N. R., \& Gates, M. F. (2001). Adults recollections of the experiences as young caregivers of family members with chronic physical illnesses. Journal of Advanced Nursing, 34(3), 320-328.

McClure, L. (2001). School-age caregivers: Perceptions of school nurses working in central England. The Journal of School Nursing, 17, 76. doi: 10.1177/105984050101700204

Merrell, J., Kinsella, F., Murphy, F., Philpin, S., \& Ali, A. (2005). Support needs of carers of dependent adults from a Bangladeshi community. Journal of Advanced Nursing, 51(6), 549-557.

Metzing-Blau, S., \& Schnepp, W. (2008). Young carers in Germany: To live on as normal as possible - a grounded theory study. BMC Nursing, 7, 15. doi: 10.1186/1472-6955-7-15

Newman, T. (2002). Young carers' and disabled parents: Time for a change of direction? Disability \& Society, 17(6), 613-625. 
Pakenham, K. I., Chiu, J., Bursnall, S., \& Connon, T. (2007). Relations between social support, appraisal and coping and both positive and negative outcomes in young carers. Journal of Health Psychology, 12(1), 89-102. doi: 10.1177/1359105307071743

Ramirez, T.R. (2013). Adolescents gaining awareness and overcoming the socialization of gender roles. A five-day gender role awareness workshop for high school students. (Master of Science in Counseling project). California State University, Northridge). Retrieved from: http://scholarworks.csun.edu/bitstream/handle/10211.2/3193/ ADOLESCENTS GAININGAWARENESSANDOVERCOMINGTHESOCIALIZATIONOFGENDERRO LES.pdf? sequence=1 . October 10, 2014

Richardson, K., Jinks, A., \& Roberts, B. (2009). Qualitative evaluation of a young carers' initiative. Journal of Child Health Care, 13(2), 150-160. doi: $10.1177 / 1367493509192475$

Robson, E. (2004). Hidden child workers: Young carers in Zimbabwe. Antipode, 36(2), 227-248.

Rose, H. D., \& Cohen, K. (2010). The experiences of young carers: A meta-synthesis of qualitative findings. Journal of Youth Studies, 13(4), 473-487.

Shifren, K., \& Kachorek, L. V. (2003). Does early caregiving matter? The effects on young caregivers' adult mental health. International Journal of Behavioral Development, 27(4), 338-346.

Skovdal, M. (2010). Children caring for their "caregivers": Exploring the caring arrangements in households affected by AIDS in Western Kenya. AIDS Care, 22(1), 96-103.

Stewart, F. \& Patterson, E. (2010). Caring in Scotland: Analysis of existing data sources on unpaid carers in Scotland. Edinburgh, UK: Scottish Government Social Research. Retrieved from http://www.scotland.gov.uk/Resource/Doc/319592/0102111.pdf. October $10,2014$.

Valleau, M. P., Bergner, R. M., \& Horton, C. B. (1995). Parentification and caretaker syndrome: An empirical investigation. Family Therapy: The Journal of the California Graduate School of Family Psychology, 22(3), 157-164.

Waugh E, Szafran O, Duerksen K, Torti J, Charles G, Shankar S. Is there a care gap for young carers in Canada? Edmonton community agencies' perspectives. Canadian Journal of Family and Youth. Accepted May 27, 2014

Warren, J. (2007). Young carers: Conventional or exaggerated levels of involvement in domestic and caring tasks? Children \& Society, 21(2), 136-146. 